\title{
Impaired Arterial Smooth Muscle Cell Vasodilatory Function In Methamphetamine Users
}

\footnotetext{
Ghaemeh Nabaei,M D ${ }^{1 *}$, Farzad Fatehi ${ }^{1}$, Askar Ghorbani ${ }^{1}$, Shahram Oveisgharan ${ }^{1}$

${ }^{1}$ Iranian Center of Neurological Research, Shariati Hospital, Tehran University of Medical Sciences, Tehran, Iran.

*Corresponding Author: Email: Nabaei.gh@gmail.com
}

\section{Objectives:}

M ethamphetamine use is a strong risk factor for stroke. This study was designed to evaluate arterial function and structure in methamphetamine users ultrasonographically.

\section{Methods:}

In a cross-sectional study, 20 methamphetamine users and 21 controls, aged between 20 and 40years, were enrolled. Common carotid artery intima-media thickness (CCA-IMT) marker of early atherogenesis, flow-mediated dilatation (FM D) determinants of endothelium-dependent vasodilation, and nitroglycerine-mediated dilatation (NMD) independent marker of vasodilation were measured in two groups.

\section{Results:}

There were no significant differences between the two groups regarding demographic and metabolic characteristics. The mean ( $\pm \mathrm{SD}$ ) CCA-IM T in methamphetamine users was $0.58 \pm 0.09 \mathrm{~mm}$, versus $0.59 \pm 0.07 \mathrm{~mm}$ in the controls $(p=0.84)$. Likewise, FM D\% was not significantly different between the two groups [7.6 $\pm 6.1 \%$ in methamphetamine users vs. $8.2 \pm 5.1 \%$ in the controls; $p=0.72$ ], nor were peak flow and shear rate after hyperemia. However, NM D\% was considerably decreased in the methamphetamine users [ $8.5 \pm 7.8 \%$ in methamphetamine users vs. $13.4 \pm 6.2 \%$ in controls; $p=0.03$ ].

\section{Conclusion:}

According to our results, NMD is reduced among otherwise healthy methamphetamine users, which represents smooth muscle dysfunction in this group. This may contribute to the high risk of stroke among methamphetamine users.

Key words: arterial smooth muscle ,vasodilatory function

DOI: $10.7575 /$ aiac.abcmed.ca1.71 